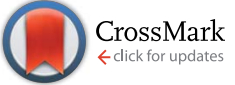

Cite this: RSC Adv., 2017, 7, 1869

Received 1st November 2016 Accepted 8th December 2016

DOI: 10.1039/c6ra26134e

www.rsc.org/advances

\section{Scavenging ability of dendritic PAMAM bridged hindered phenolic antioxidants towards DPPH and ROO` free radicals}

\begin{abstract}
Cuiqin Li, Peng Sun, Hongyang Yu, Na Zhang and Jun Wang*
Antioxidant activities of first generation and the second generation dendritic antioxidants (1.0G and 2.0G dendritic antioxidants) with a hindered phenolic group and a tertiary amine group at the same molecule were evaluated using the $\mathrm{DPPH}^{*}$ method and the oxygen uptake method. It was found that two dendritic antioxidants had good scavenging abilities on $\mathrm{DPPH}^{\circ}$ and $\mathrm{ROO} \mathrm{O}^{\circ}$ free radicals and their scavenging abilities were superior to Irganox 3114 with only hindered phenol groups. The antioxidant abilities of dendritic skeletons which only contained the tertiary amine groups were evaluated and they might scavenge $\mathrm{DPPH}^{\circ}$ and $\mathrm{ROO}^{*}$ free radical. The results of dendritic skeletons showed that dendritic antioxidants were the intramolecular complex primary antioxidants with hindered phenolic group and tertiary amine group, and they have good synergistic effect.
\end{abstract}

\section{Introduction}

Antioxidants are widely added to organic materials to prevent the compounds from degrading and losing their properties as they are exposed to oxygen, heat and light..$^{1-3}$ The most primary antioxidants are hindered phenolic antioxidants and amine antioxidants which could terminate free radicals produced in the process of thermal oxidation. ${ }^{4}$ Nowadays it is well known that phenolic compounds play a key role as antioxidants due to the presence of hydroxyl substituents and their aromatic structure, which enables them to scavenge free radical. And moreover many studies ${ }^{5-7}$ showed that combining different antioxidants gives a mutual protective effect. Shi and coworkers ${ }^{8}$ studied the antioxidant property of lycopene, $\beta$-carotene, vitamins $\mathrm{C}$ and $\mathrm{E}$, individually or in combination. The results showed that in a homogenous solution of linoleic acid methyl ester the combination of lycopene and vitamin $\mathrm{E}$ exhibited a greater inhibitory effect than the additive effect of individual antioxidants, while the combination of $\beta$-carotene and vitamin $\mathrm{E}$ did not produce a similar synergistic effect. Liu and co-workers ${ }^{9}$ studied the antioxidant property of the combination of natural antioxidants using the 2,2-diphenyl-1picrylhydrazyl ( $\mathrm{DPPH}^{\circ}$ ) free radical method and the results showed that the antioxidant property of the combination of natural antioxidants was substantially superior to the sum of the individual antioxidant effects, and indicated the combination of the antioxidants exhibited good synergistic effect.

Provincial Key Laboratory of Oil \& Gas Chemical Technology, College of Chemistry \& Chemical Engineering, Northeast Petroleum University, Daqing, 163318, China. E-mail: dqpilicuiqin@126.com; Fax: +860459 6504224; Tel: +8604596504224
However, the combination between different antioxidants might result in the decrease of antioxidant ability. Compounds with different antioxidant groups in the same molecule act as potent antioxidants which have intramolecular synergistic effects by different antioxidant groups. ${ }^{10-12}$ Wang and coworkers ${ }^{13}$ synthesized a new intermolecular complex antioxidant [3-(3,5-di-tert-butyl-4-hydroxy-phenyl)] propionyl phosphoric acid bisoctadecanol ester with phenol and phosphite groups, and the results showed that the antioxidant ability of the intermolecular complex antioxidant in polyolefin was superior to that of $n$-octadecyl- $\beta$-(3,5-di-tert-butyl-4hydroxyphenyl)-propionate (Irganox 1076). Nishiyama and coworkers $^{14}$ investigated intramolecular synergistic effects between chromanol and thiopropionate groups of a series of antioxidants in tetralin oxidation, and the results showed that there were good intramolecular synergistic effects between chromanol and thiopropionate groups. These antioxidants were the compounds with primary antioxidant and secondary antioxidant in the same molecule. However, little works has been done on hindered phenol and tertiary amine groups in the same molecule.

In a previous paper, we reported that two dendritic antioxidants with hindered phenol and tertiary amine groups at the same molecule were synthesized and their antioxidant activities were better than that of 1,3,5-tri(3,5-di-tert-butyl-4hydroxybenzyl) isocyanurate (Irganox 3114) and pentaerythritol tetrakis 3-(3,5-di-tert-butyl-4-hydroxyphenyl) propionate (Irganox 1010) in polyolefins. ${ }^{15}$ However, the intramolecular synergistic effects between hindered phenol group and tertiary amine group were not investigated. The aim of this work is trying to investigate the intramolecular synergistic effects and the scavenging ability on $\mathrm{DPPH}^{*}$ and $\mathrm{ROO}^{*}$ free radical of the 
dendritic antioxidants by $\mathrm{DPPH}^{-}$method and oxygen uptake method. And moreover the proposal antioxidant mechanism was analysized.

\section{Experimental}

\subsection{Materials}

1,1-Diphenyl-2-picrylhydrazyl radical (DPPH') was purchased from Beijing Jingkehongda Biotechnology Co. Ltd. (China). Irganox 3114 purchased from Ciba Specialty Chemicals (Shanghai, China) was chemical reagent grade. Styrene, toluene and ethanol purchased from Tianjin Kemiou Chemical regent development center (China) were all of analytical reagent grade. Half-generation dendritic skeletons (0.5G PAMAM and 1.5G PAMAM) with ammonia as core and the first generation and the second generation dendrimer bridged hindered phenolic antioxidants (1.0G dendritic antioxidant and 2.0G dendritic antioxidant) were synthesized in our laboratory. ${ }^{15,16}$

\subsection{Scavenging capacity of dendritic antioxidants on $\mathrm{DPPH}^{*}$}

$\mathrm{DPPH}^{*}$ scavenging capacity was carried out using a modified method as described by Brand-Williams. ${ }^{17} \mathrm{DPPH}^{\circ}$ solution in ethanol was prepared daily and stored in the dark. Briefly, $2 \mathrm{~mL}$ samples of antioxidants dissolved in ethanol were added

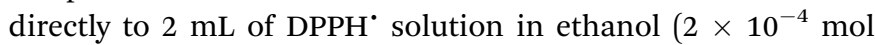
$\mathrm{L}^{-1}$ ), and then immediately shaken thoroughly. Absorbance of the mixture at $517 \mathrm{~nm}$ was recorded at different time intervals. The percentage of $\mathrm{DPPH}^{*}$ scavenging at the different time was calculated using eqn (1).

$$
\% \mathrm{DPPH}^{\cdot}=E^{\%}=\left(\frac{A_{0}-A_{t}}{A_{0}}\right) \times 100
$$

$A_{0}$ and $A_{t}$ were the absorbance at $517 \mathrm{~nm}$ of the mixture solution at the beginning and at the certain time. $\mathrm{EC}_{50}$ was defined as the antioxidant concentration needed to reduce $50 \%$ of $\mathrm{DPPH}^{\cdot}$. Time needed to reach the steady state at the concentration $\mathrm{EC}_{50}$ is named $\mathrm{TC}_{50}$. The antioxidant efficacy $(\mathrm{AE})$ that combines both $\mathrm{EC}_{50}$ and $\mathrm{TC}_{50}$ factors was calculated using eqn (2).

$$
\mathrm{AE}=\frac{1}{\mathrm{EC}_{50} \times \mathrm{TC}_{50}}
$$

\subsection{Inhibition of dendritic antioxidants on AIBN-induced oxidation of styrene}

Briefly, the rate of oxygen uptake was measured under oxygen in a closed stainless steel autoclave of $50 \mathrm{~mL}$. AIBN and antioxidant were dissolved directly in toluene. The process of AIBNinduced peroxidation of styrene was followed by an oxygen consumption apparatus equipped with an oxygen pressure gauge sensitive to oxygen pressure. Styrene in the toluene solution and antioxidant solution were put into a stainless steel autoclave which was charged with dry nitrogen three times and then was purged by oxygen, and the mixture was stirred for $10 \mathrm{~min}$ at $50^{\circ} \mathrm{C}$. The AIBN solution was injected to the mixture with a syringe in order to initiate the peroxidation of styrene. The initial concentrations of AIBN and styrene were $24 \mathrm{mM}$ and
$0.765 \mathrm{M}$, respectively. Every experiment was repeated at least three times with the standard deviation within $10 \%$, and the final data were the average values from the three independent measurements.

\section{Result and discussion}

\subsection{Radical scavenging abilities of dendritic antioxidants towards DPPH'}

Scavenging ability of hindered phenolic antioxidants on DPPH' were affected not only by the concentration of phenolic hydroxyl group but also by the reaction time and the reaction temperature. Generally speaking, radical scavenging ability of hindered phenolic antioxidants increase with increasing of the concentration of phenolic hydroxyl group in the reaction system. Scavenging ability increases firstly with an increase of reaction time, and then keep constant when the reaction time reaches a certain value. The effect of reaction temperature on scavenging ability in the scavenging $\mathrm{DPPH}^{-}$system was little because the scavenging process was exothermic reaction. ${ }^{18}$ So the effects of the concentration of antioxidant and the reaction time on scavenging capacities at the temperature of $30^{\circ} \mathrm{C}$ were investigated in this paper (Fig. 1).

Due to its stable nitrogen radical, many hindered phenol antioxidants might react with different kinetics or might not react at all. Moreover, the reaction between $\mathrm{DPPH}^{\circ}$ and antioxidant was reversible. Therefore, the antioxidant capacity of many antioxidants likely to be wrongly estimated when the scavenging reaction was based on fixed time ranging from 20$30 \mathrm{~min}$ instead of total reaction time that is required to attain steady state to complete this reaction. In this study, the effects of the molar ratio of antioxidant to $\mathrm{DPPH}^{*}$ on the percentage of $\mathrm{DPPH}^{\cdot}$ scavenging were investigated at steady state reaction time (Fig. 1(a)) when the concentration of $\mathrm{DPPH}^{\circ}$ was $1 \times$ $10^{-4} \mathrm{~mol} \mathrm{~L}^{-1}$. And the percentage of $\mathrm{DPPH}^{\cdot}$ scavenging increased rapidly and then kept constant with increasing the molar ratio of antioxidant to $\mathrm{DPPH}^{*}$ at steady state reaction time. This was due to that dendritic antioxidants with big steric hindrance were polyphenolic compounds and reversibility of reaction between antioxidant and $\mathrm{DPPH}^{\circ}$. The scavenging effect of $1.0 \mathrm{G}$ dendritic antioxidant was superior to that of Irganox 3114 with the same number of phenolic hydroxyl group, and the scavenging effect of $2.0 \mathrm{G}$ dendritic antioxidant was superior to that of $1.0 \mathrm{G}$ dendritic antioxidant at the same molar ratio of antioxidant to DPPH ${ }^{*}$. This could be caused by dendritic antioxidants with hindered phenolic groups and tertiary amine groups were intramolecular complex antioxidants, and they could terminate the DPPH radical not only by donating $\mathrm{H}$-atoms but also by electron transfer. The $\mathrm{EC}_{50}$ values (Table 1) of dendritic antioxidants were obtained by the curve fitting to the Fig. 1(a).

The effects of reaction time on the $E \%$ value at the concentration $\mathrm{EC}_{50}$ were shown in Fig. $1(\mathrm{~b})$. The $E \%$ values of the system with antioxidant increased quickly and then increased slowly with increasing of reaction time. Times reached the steady state for $1.0 \mathrm{G}$ dendritic antioxidant, 2.0G dendritic antioxidant and Irganox 3114 were $116.98 \mathrm{~min}, 109.12 \mathrm{~min}$ and 


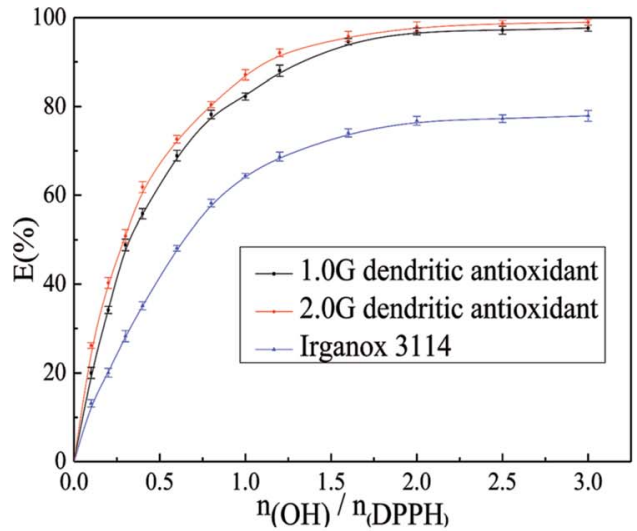

(a)

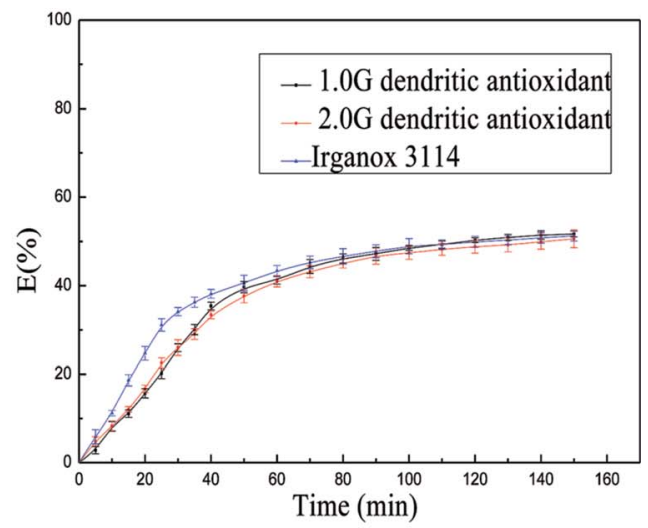

(b)

Fig. 1 Effect of the reaction conditions on the scavenging activity of dendritic antioxidants.

Table 1 Parameters of scavenging capacity of dendritic antioxidants

\begin{tabular}{llll}
\hline Antioxidant & $\begin{array}{l}\mathrm{EC}_{50}(n(\text { antioxidant }) / \\
n(\mathrm{DPPH})\end{array}$ & $\begin{array}{l}\mathrm{TC}_{50} \\
(\mathrm{~min})\end{array}$ & $\mathrm{AE} \times 10^{-3}$ \\
\hline 1.0G dendritic antioxidant & 0.32 & 116.98 & 2.67 \\
2.0G dendritic antioxidant & 0.29 & 109.12 & 3.16 \\
Antioxidant 3114 & 0.64 & 125.47 & 1.24 \\
\hline
\end{tabular}

$125.47 \mathrm{~min}$, respectively. And the $E \%$ values of the three antioxidants at the time of the steady state were $50.01 \%, 48.17 \%$, and $50.00 \%$, respectively. The results showed that the reactions between dendritic antioxidants and $\mathrm{DPPH}^{*}$ were slow, and the larger the steric hindrance is, the harder the reaction between antioxidant and $\mathrm{DPPH}^{\circ} .{ }^{19} \mathrm{TC}_{50}$ values of dendritic antioxidants were obtained by the curve fitting to the Fig. 1(b).

$\mathrm{EC}_{50}$ value is inversely related to the antioxidant capacity of the antioxidant, and the lower the $\mathrm{EC}_{50}$ value, the higher the antioxidant activity of the antioxidant is. $\mathrm{TC}_{50}$ value is related to the rate between antioxidant and $\mathrm{DPPH}^{\circ}$ and the lower $\mathrm{TC}_{50}$ value, the faster the reaction rate is. The $\mathrm{EC}_{50}$ values of two dendritic antioxidants were lower than that of Irganox 3114, and this indicated that the antioxidant activities of two dendritic antioxidants were higher. Moreover, the $\mathrm{EC}_{50}$ and $\mathrm{TC}_{50}$ values of 2.0G dendritic antioxidant were lower than those of $1.0 \mathrm{G}$ dendritic antioxidant. The possible reason was that total $\mathrm{H}$ atom donating capacities of $2.0 \mathrm{G}$ dendritic antioxidant with six hindered phenolic groups in a molecule were higher, and the tertiary amine groups of $2.0 \mathrm{G}$ dendritic antioxidant might scavenge $\mathrm{DPPH}^{*}$ radical by electron transfer.

$\mathrm{DPPH}^{*}$ method permits to evaluate not only the electron- or hydrogen atom-donating properties of antioxidants $\left(\mathrm{EC}_{50}\right)$, but also the rate of their reaction towards the free radicals $\left(\mathrm{TC}_{50}\right)$. Villaño and co-worker ${ }^{20}$ investigated radical scavenging ability of a series of polyphenolic compounds using $\mathrm{DPPH}^{\circ}$ assay and the results showed that polyphenolic compounds with a high $\mathrm{EC}_{50}$ value had low $\mathrm{TC}_{50}$ value. However, dendritic antioxidant with a high $\mathrm{EC}_{50}$ value had a low reaction rate with $\mathrm{DPPH}^{*}$. The $\mathrm{AE}$ values of two dendritic antioxidants were calculated and were listed in Table 1 . The $\mathrm{AE}$ is a parameter that combined both $\mathrm{EC}_{50}$ and $\mathrm{TC}_{50}$. The larger the $\mathrm{AE}$ value is, the higher the scavenging ability of antioxidants on DPPH free radial is. The $\mathrm{AE}$ values of dendritic antioxidants were higher than that of Irganox 3114. Moreover, the AE value of 1.0G dendritic antioxidant was twice higher than that of Irganox 3114, and the $\mathrm{AE}$ value of 2.0G dendritic antioxidant was over twice higher than that of Irganox 3114. However, the structures of antioxidants (Fig. 2) showed that the number of phenolic group of $1.0 \mathrm{G}$ dendritic antioxidant was the same as that of Irganox 3114, and that of 2.0G dendritic antioxidant was as twice as that of $1.0 \mathrm{G}$ dendritic antioxidant (Fig. 2). The results indicated that not only the phenolic group of dendritic antioxidants might terminate free radicals, but also the tertiary amine group might terminate free radicals. Tertiary amine group connected with alkyl chain, and electron-donating ability made electron density of $\mathrm{N}$ atom in tertiary amine group increase and easy to terminate free radicals through electron transfer. 2.0G dendritic antioxidant had four tertiary group, while 1.0G dendritic antioxidant bears only one tertiary group. So the value of $E \%$ for 2.0G dendritic antioxidant was higher. Dendritic antioxidants are new bifunctional antioxidants which have intramolecular synergistic effects between phenol and tertiary amine groups.

\subsection{Free scavenging abilities of dendritic antioxidants towards ROO}

Though $\mathrm{DPPH}^{\cdot}$ method may evaluate antioxidant activity of hindered phenols, the $\mathrm{DPPH}^{*}$ free radical was a stable radical and the antioxidant capacity of many antioxidants with lower activity likely to be wrongly estimated. In order to investigate the antioxidant ability of dendritic antioxidants, the high active peroxyl radicals in the process of the initiation of AIBN-induced oxidation of styrene in the oxygen system were used..$^{21,22}$ Peroxyl radicals ( $\mathrm{ROO}^{\circ}$ ) generate in AIBN-induced oxidation of styrene. With an antioxidant adding to the reaction system, the antioxidant trap the peroxyl radical (ROO') to generation an antioxidant radical $\left(\mathrm{A}^{\circ}\right)$, and the antioxidant radical might couple rapidly with the peroxyl (ROO') to form the nonradical product. The radical-induced oxidation of styrene is inhibited until all 
<smiles>CC(C)(C)c1cc(Cn2c(=O)n(Cc3cc(C(C)(C)C)c(O)c(C(C)(C)C)c3)c(=O)n(Cc3cc(C(C)(C)C)c(O)c(C(C)(C)C)c3)c2=O)cc(C(C)(C)C)c1O</smiles>

Irganox 3114

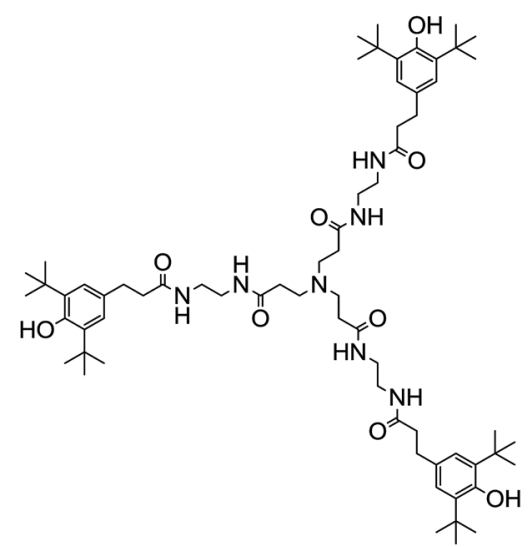

$1.0 \mathrm{G}$ dendritic antioxidant

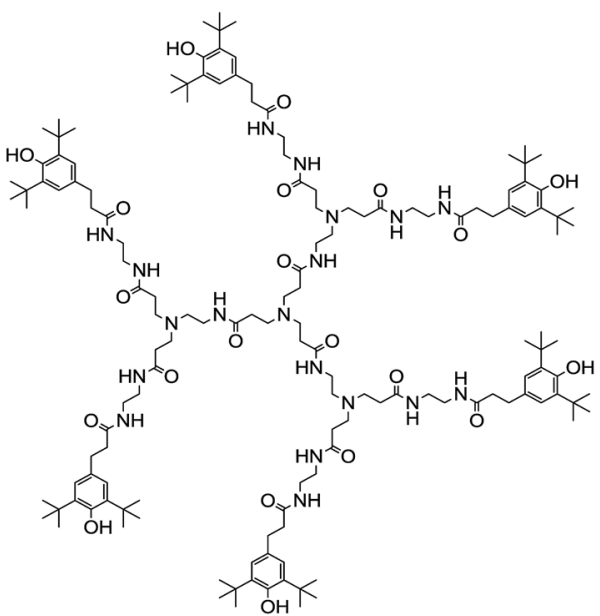

2.0G dendritic antioxidant

Fig. 2 Chemical structures of antioxidants.

the antioxidant is depleted. The oxygen consumption rate increases rapidly in the period of propagation in absence of antioxidant, and the oxygen consumption rate decreases with antioxidant adding. The oxygen uptake curves of the initiation of AIBN-induced oxidation of styrene in the presence of various concentrations of dendritic antioxidants were shown in Fig. 3.

The initiation reaction, chain propagation reaction and chain termination reaction of styrene under oxygen system were treated on the basis of the steady-state hypothesis, in which the concentrations of the radicals remain constant. The rate of oxygen exhaustion during the oxidation of styrene $(\mathrm{RH})$ in absence of antioxidant is described as $R_{\mathrm{p}}$ correlating with the rate of radical initiation $\left(R_{\mathrm{i}}\right)$ and the concentration of $\mathrm{RH}$ as shown in the following equation:

$$
R_{\mathrm{p}}=-\mathrm{d}\left[\mathrm{O}_{2}\right] / \mathrm{d} t=\left(k_{\mathrm{p}} /\left(2 k_{t}\right)^{0.5}\right) R_{\mathrm{i}}^{0.5}[\mathrm{LH}]
$$

where $k_{\mathrm{p}} /\left(2 k_{t}\right)^{0.5}$ is referred to as the oxidizability of styrene, representing the susceptibility of styrene to undergo peroxidation. $R_{\mathrm{i}}$ is the initiation rate which is $2.64 \times 10^{-6}$ times as many as the concentration of the initiator AIBN. $k_{\mathrm{p}}$ is the rate constant of chain propagation of styrene and the $k_{\mathrm{p}}$ value is 238 $\mathrm{M}^{-1} \mathrm{~S}^{-1}$ at $50^{\circ} \mathrm{C}$ in toluene. $R_{\mathrm{p}}$ is the slope of the CD segment in Fig. 3. With dendritic antioxidant adding to the reaction system, antioxidant can prevent these radicals from propagating the chain reaction by donating $\mathrm{H}$-atoms to the free radicals and an inhibition period $\left(t_{\mathrm{inh}}\right)$ was generated. The rate of oxygen exhaustion in the presence of dendritic antioxidant is described by eqn (4).

$$
-\mathrm{d}\left[\mathrm{O}_{2}\right] / \mathrm{d} t=R_{\text {inh }}=k_{\mathrm{p}}[\mathrm{LH}] /\left(t_{\mathrm{inh}} k_{\mathrm{inh}}\right)
$$

where $k_{\mathrm{p}}$ is referred to the reaction rate constant in the period of propagation, $k_{\mathrm{inh}}$ is referred to the rate constant in the period of inhibition and is one of the key factors for evaluating an antioxidant by oxygen uptake, $R_{\mathrm{inh}}$ is the slope of the BC segment in Fig. 3. Besides the kinetic parameters for evaluating the antioxidant ability of the dendritic antioxidants, the kinetic chain length $(\mathrm{kcl})$ is applied to assess the antioxidant capacity. The inhibition kinetic chain length $\left(\mathrm{kcl}_{\mathrm{inh}}\right)$ and the propagation kinetic chain length $\left(\mathrm{kcl}_{\mathrm{p}}\right)$ define the cycle number of chain propagating in the period of inhibition and propagation and can be expressed as the eqn (5) and (6).

$$
\begin{gathered}
\mathrm{kcl}_{\text {inh }}=R_{\text {inh }} / R_{\mathrm{i}} \\
\mathrm{kcl}_{\mathrm{p}}=R_{\mathrm{p}} / R_{\mathrm{i}}
\end{gathered}
$$

The kinetic parameters in the presence of dendritic antioxidants or Irganox 3114 are collected in Table 2. The propagation kinetic parameters, such as $R_{\mathrm{p}}, k_{\mathrm{p}} /\left(2 k_{t}\right)^{0.5}$ and $\mathrm{kcl}_{\mathrm{p}}$ decreased with the increase of the concentration of dendritic antioxidants, and the results showed that dendritic antioxidants scavenging the ROO' by donating $\mathrm{H}$-atoms and inhibited the AIBN-induced peroxidation of styrene. The kinetic parameter of $k_{\text {inh }}$, which indicated the antioxidant capacity of dendritic antioxidants, increased with increasing of the concentration of antioxidants, and the results demonstrated that the higher the concentrations of dendritic antioxidants or Irganox 3114, the more markedly the styrene is protected by antioxidants. As for $\mathrm{kcl}_{\mathrm{p}}$ and $\mathrm{kcl}_{\mathrm{inh}}$, it can be found that the addition of various antioxidants shortens the cycles of radical propagation significantly. Moreover, the $\mathrm{kcl}_{\mathrm{p}}$ and $\mathrm{kcl}_{\mathrm{inh}}$ values decreased with increasing of the concentration of antioxidants. At the same concentration of phenolic hydroxyl group, the order of $\mathrm{kcl}_{\text {inh }}$ values for the three antioxidants was $2.0 \mathrm{G}$ dendritic antioxidant $>1.0 \mathrm{G}$ dendritic antioxidant $>$ Irganox 3114 , but the order of $R_{\text {inh }}$ values for the three antioxidants was $2.0 \mathrm{G}$ dendritic antioxidant $>$ Irganox $3114>1.0 \mathrm{G}$ dendritic antioxidant (at the two lower concentrations) when the concentration of phenolic hydroxyl groups was low, the phenolic hydroxyl through donating $\mathrm{H}$ atom as a main pathway to terminating free radicals. While the influence of phenolic hydroxyl did not changed significantly with the increase of concentration of antioxidant and tertiary 


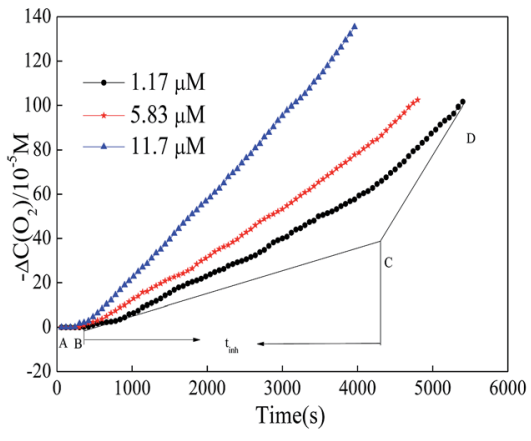

(a) $1.0 \mathrm{G}$ dendritic antioxidant

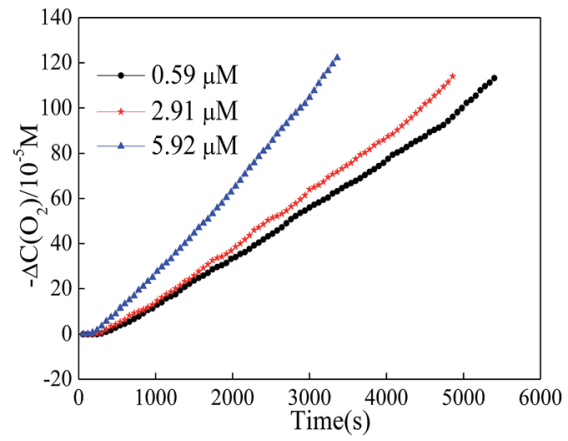

(b) 2.0G dendritic antioxidant

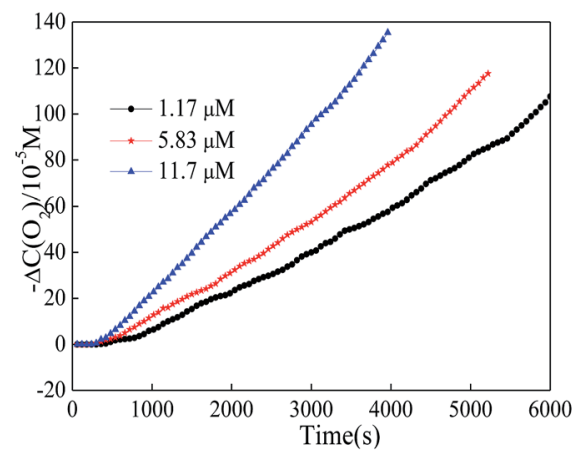

(c) Irganox 3114

Fig. 3 Oxygen consumption curve of the initiation of AIBN-induced oxidation of styrene for antioxidants.

Table 2 Inhibition kinetic parameters of antioxidant on AIBN-induced peroxidation of styrene ${ }^{a}$

\begin{tabular}{|c|c|c|c|c|c|c|c|}
\hline Antioxidant & $\begin{array}{l}\text { Concentration } \\
(\mu \mathrm{M})\end{array}$ & $\begin{array}{l}R_{\mathrm{p}} \\
\left(10^{-8} \mathrm{M} \mathrm{s}^{-1}\right)\end{array}$ & $\begin{array}{l}R_{\text {inh }} \\
\left(10^{-8} \mathrm{M} \mathrm{s}^{-1}\right)\end{array}$ & $\begin{array}{l}k_{\mathrm{p}} /\left(2 k_{t}\right)^{0.5} \\
\left(10^{-3}\right)\end{array}$ & $\begin{array}{l}k_{\text {inh }} \\
\left(10^{5} \mathrm{M}^{-1} \mathrm{~s}^{-1}\right)\end{array}$ & $\mathrm{kcl}_{\mathrm{p}}$ & $\mathrm{kcl}_{\text {inh }}$ \\
\hline \multirow[t]{2}{*}{ 1.0G dendritic antioxidant } & 1.17 & 18.7 & 16.0 & 0.97 & 7.55 & 2.95 & 2.52 \\
\hline & 11.7 & 10.42 & 5.04 & 0.54 & 19.01 & 1.64 & 0.79 \\
\hline \multirow[t]{2}{*}{ 2.0G dendritic antioxidant } & 0.59 & 22.7 & 16.23 & 1.18 & 5.94 & 3.58 & 2.56 \\
\hline & 2.91 & 14.5 & 9.29 & 0.75 & 9.17 & 2.29 & 1.47 \\
\hline & 5.83 & 12.97 & 7.67 & 0.67 & 13.96 & 2.04 & 0.97 \\
\hline & 11.7 & 11.05 & 5.18 & 0.57 & 18.83 & 1.74 & 0.66 \\
\hline
\end{tabular}

${ }^{a} R_{\mathrm{i}}=R_{\mathrm{g}}=2.64 \times 10^{-6}[\mathrm{AIBN}] \mathrm{s}^{-1}=6.34 \times 10^{-8} \mathrm{M} \mathrm{s}^{-1},[\mathrm{AIBN}]=24 \mathrm{mM},[\mathrm{LH}]=0.765 \mathrm{~mol} \mathrm{~L}^{-1}$.

amine played a vital role in terminating free radicals. This was the reason that the ranking matches with the data of Table 2 for the two lower concentrations, but not for the highest concentration.

Besides the above kinetic parameters, the number of trapping $\operatorname{ROO}^{\circ}(n)$ is always applied to assess the antioxidant capacity. Table 3 involves $t_{\text {inh }}$ in the different concentration of antioxidants, and moreover, the relationships between $t_{\text {inh }}$ and the concentration of antioxidants are found and listed in Table 2 . The $n$ values of three antioxidants can be obtained by the relationships between $t_{\text {inh }}$ and the concentration of antioxidants and listed in Table 3 as well. The $n$ value of $1.0 \mathrm{G}$ dendritic antioxidant was higher than that of Irganox 3114, and the $n$ value of $2.0 \mathrm{G}$ dendritic antioxidant was highest of the three antioxidants. Moreover, the $n$ value of $2.0 \mathrm{G}$ dendritic antioxidant was nearly three times than that of $1.0 \mathrm{G}$ dendritic antioxidant. However, the phenolic groups of $2.0 \mathrm{G}$ dendritic antioxidant was twice as many as that of $1.0 \mathrm{G}$ dendritic antioxidant. The fact reveals that dendritic antioxidants could terminate the ROO' not only by donating $\mathrm{H}$-atoms of the phenolic groups but also by electron transfer of the tertiary amine groups (Fig. 4). 1.0G dendritic antioxidant has three hindered phenolic groups and a tertiary amine group, and 2.0G dendritic antioxidant has six hindered phenolic groups and four tertiary amine groups. But 2.0G dendritic antioxidant possesses bulkier branches caused a decrease in activity as compared to the $1.0 \mathrm{G}$ dendritic antioxidant. The above mentioned observation can be associated to the effect of the 
Table 3 Equation of $t_{\mathrm{inh}} \sim[\mathrm{AH}]$ and $n$ of antioxidants in protecting styrene against AIBN-induced oxidation ${ }^{a}$

\begin{tabular}{lcl}
\hline Antioxidant & $t_{\mathrm{inh}}(\mathrm{s})=\left(n / R_{\mathrm{i}}\right)[$ antioxidant $(\mu \mathrm{M})]+$ constant & $n$ \\
\hline 1.0G dendritic antioxidant & $t_{\mathrm{inh}}=39.9[$ antioxidant $]+1473.6\left(r^{2}=0.9874\right)$ & 2.5 \\
2.0G dendritic antioxidant & $t_{\mathrm{inh}}=107.4[$ antioxidant $]+1799.1\left(r^{2}=0.9966\right)$ & 6.8 \\
Antioxidant 3114 & $t_{\mathrm{inh}}=35.1\left[\right.$ antioxidant] $+1510.1\left(r^{2}=0.9910\right)$ & 2.2 \\
${ }^{a} R_{\mathrm{i}}=R_{\mathrm{g}}=6.34 \times 10^{-8} \mathrm{M} \mathrm{s}^{-1}, n=$ coefficient $\times 6.34 \times 10^{-8} \mathrm{M} \mathrm{s}^{-1}$. &
\end{tabular}

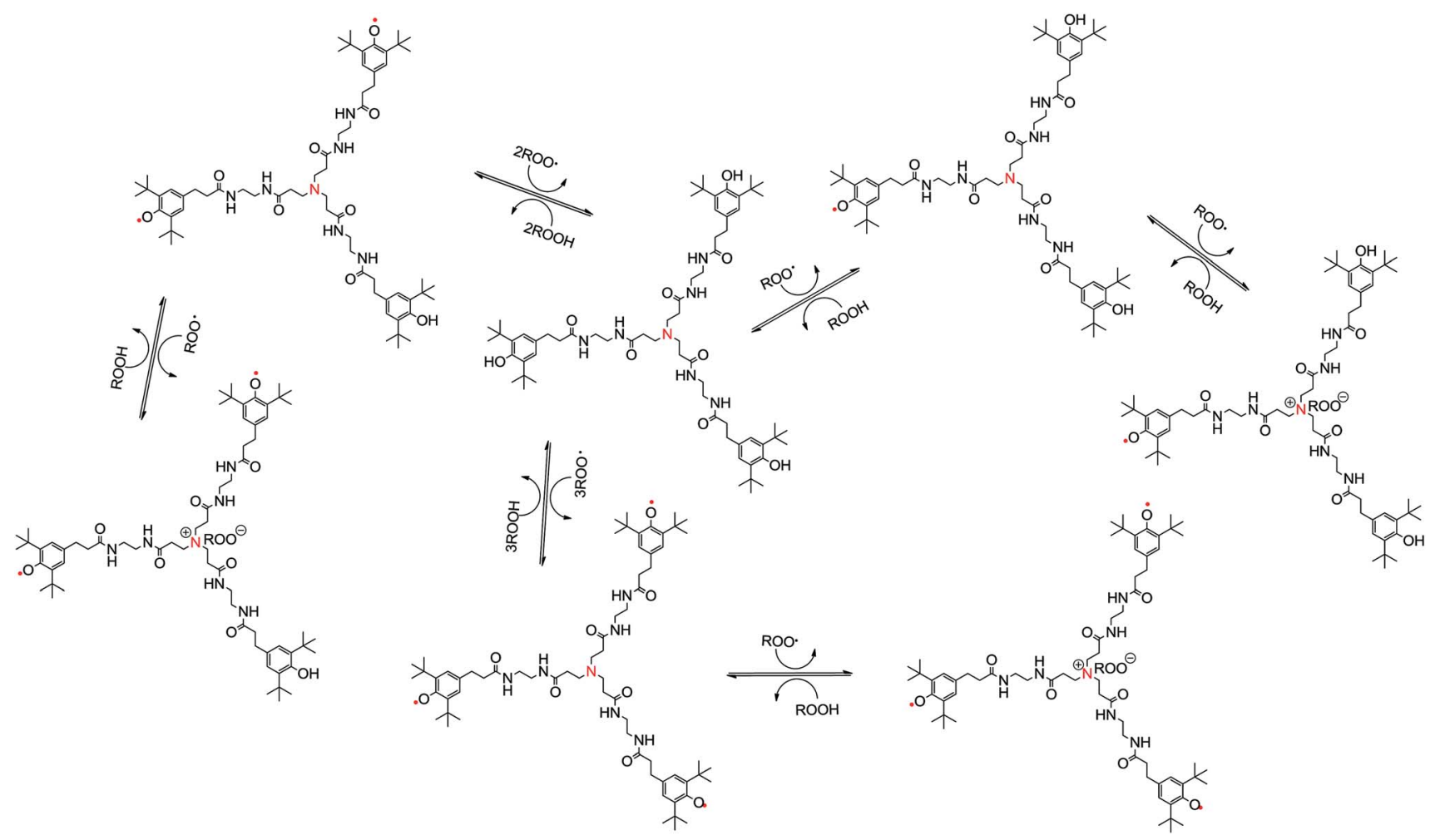

Fig. 4 Possible scavenging reaction mechanism of $1.0 \mathrm{G}$ dendritic antioxidants on ROO*

bulkier branches toward the reaction of tertiary amine groups and $\mathrm{ROO}^{\circ}$ : usually bulkier branches offer maximum resistance to $\mathrm{ROO}^{\bullet}$ coming into the tertiary amine groups.

\subsection{Intramolecular synergistic effects of dendritic antioxidants}

In order to verify the antioxidant ability of tertiary amine groups in dendritic antioxidants, we evaluated the antioxidant abilities of the skeletons (0.5G and 1.5G PAMAM) (Fig. 5) which only contained the tertiary amine group by the $\mathrm{DPPH}^{\circ}$ method (the concentration of $\mathrm{DPPH}^{-}$was $2 \times 10^{-4} \mathrm{~mol} \mathrm{~L}^{-1}$ ) and the oxygen uptake method (the concentration of $0.5 \mathrm{G}$ and 1.5G PAMAM were $11.7 \mu \mathrm{M}$ and $5.92 \mu \mathrm{M}$, respectively). The results showed that $0.5 \mathrm{G}$ and $1.5 \mathrm{G}$ PAMAM had a certain scavenging abilities of $\mathrm{DPPH}^{*}$ free radical, and the scavenging ability increased with increasing of the concentration of the skeletons (Fig. 6(a)). But the scavenging abilities of $0.5 \mathrm{G}$ and $1.5 \mathrm{G}$ PAMAM were lower. The results of the scavenging $\mathrm{ROO}^{\circ}$ revealed that the $k_{\mathrm{inh}}$ of $0.5 \mathrm{G}$ and $1.5 \mathrm{G}$ PAMAM were $8.09 \times 10^{-5} \mathrm{M}^{-1} \mathrm{~s}^{-1}$ and $8.62 \times 10^{-5}$
$\mathrm{M}^{-1} \mathrm{~s}^{-1}$, respectively (Fig. 6(b)). Moreover, the antioxidant ability of 1.5G PAMAM was higher than that of 0.5G PAMAM, and this was because the number of tertiary amine antioxidant groups of 1.5G PAMAM was four times that of 0.5G PAMAM indicating that the tertiary amine group might terminate free

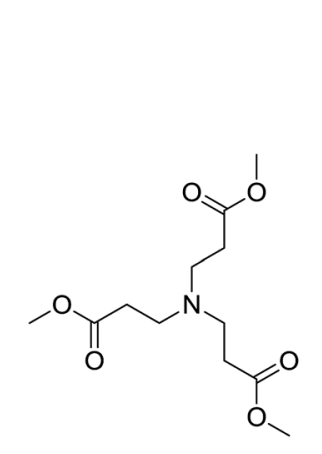

0.5G PAMAM

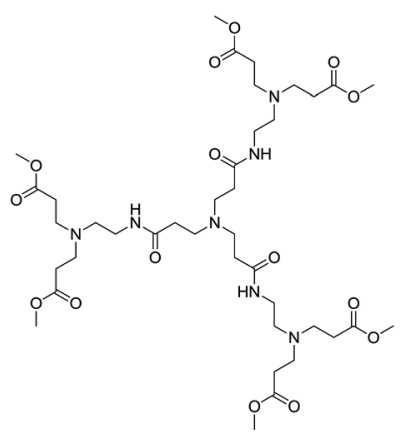

1.5G PAMAM
Fig. 5 Chemical structures of $0.5 \mathrm{G}$ and 1.5G PAMAM. 


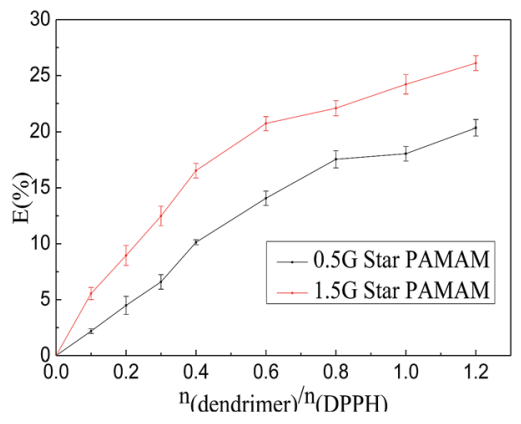

(a)

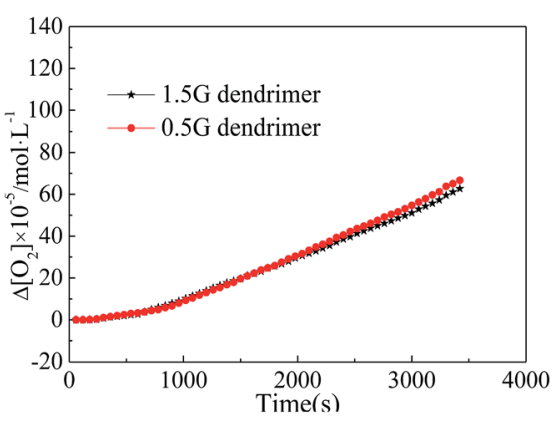

(b)

Fig. 6 Scavenging ability of $0.5 \mathrm{G}$ and $1.5 \mathrm{G}$ dendritic skeletons on $\mathrm{DPPH}$ and $\mathrm{ROO}$.

radicals. ${ }^{23,24}$ The three alkyl chains of tertiary amine have better electron-donating ability, which made the electron density on the $\mathrm{N}$ atom abundant and easy to terminate free radicals through electron transfer. Besides, the more the number of tertiary amine, the higher the scavenging ability of antioxidant. The experimental results verified that dendritic antioxidants were intramolecular complex primary antioxidants and they had intramolecular synergistic antioxidant ability. This was the reason that the antioxidant ability of $1.0 \mathrm{G}$ dendritic antioxidant was higher than that of Irganox 3114, and the antioxidant ability of $2.0 \mathrm{G}$ dendritic antioxidant was higher than that of $1.0 \mathrm{G}$ dendritic antioxidant.

\section{Conclusion}

Dendritic antioxidants with hindered phenolic group and tertiary amine groups have better scavenging abilities on $\mathrm{DPPH}^{\circ}$ and $\mathrm{ROO}^{\circ}$ free radical. The scavenging abilities of $2.0 \mathrm{G}$ dendritic antioxidant with six hindered phenol groups and four tertiary amine groups were greater than those of $1.0 \mathrm{G}$ dendritic antioxidant with three hindered phenol groups and one tertiary amine groups. In $\mathrm{DPPH}^{\circ}$ and $\mathrm{ROO}^{\circ}$ scavenging, antioxidant with dendritic structure has higher antioxidant ability than Irganox 3114 and when hindered phenol groups and tertiary amine groups exist in the molecule together, dendritic antioxidants will give out a highly synergetic effect. The scavenging abilities of $0.5 \mathrm{G}$ and $1.5 \mathrm{G}$ dendritic skeletons on the two free radicals showed that dendritic antioxidants might terminate free radicals not only by donating $\mathrm{H}$-atoms but also by electron transfer, and dendritic antioxidants with hindered phenol group and tertiary amine group in the molecule together are intramolecular synergistic antioxidants.

\section{Acknowledgements}

This work was supported by the financial foundation of National Nature Science Foundation of China (No. 51303020), Heilongjiang Education Department (No. 12521z005) and Northeast Petroleum University (No. ky120212).

\section{References}

1 R. K. Krishnaswamy, Polym. Eng. Sci., 2007, 47, 516-521.

2 X. F. Wang, W. Y. Xing, G. Tang, N. N. Hong, W. Z. Hu, J. Zhan, L. Song, W. Yang and Y. Hu, Polym. Degrad. Stab., 2013, 98, 2391-2398.

3 Z. Q. Liu, Chem. Rev., 2010, 110, 5675-5691.

4 M. Lundbäck, M. S. Hedenqvist, A. Mattozzi and U. W. Gedde, Polym. Degrad. Stab., 2006, 91, 1571-1580.

5 I. Kriston, Á. Orbán-Mester, G. Nagy, P. Staniek, E. Földes and B. Pukánszky, Polym. Degrad. Stab., 2009, 94, 719729.

6 S. Yachigo, M. Sasaki and F. Kojima, Polym. Degrad. Stab., 1992, 35, 105-113.

7 C. S. Romano, K. Abadi, V. Repetto, A. A. Vojnov and S. Moreno, Food Chem., 2009, 115, 456-461.

8 J. Shi, Q. Qu, Y. Kakuda, S. J. Xue, Y. M. Jiang, S. Koide and Y. Y. Shim, J. Food Compos. Anal., 2007, 20, 603-608.

9 D. Liu, J. Shi, A. C. Ibarra, Y. Kakuda and S. J. Xue, LWT-Food Sci. Technol., 2008, 41, 1344-1349.

10 I. Bauer, W. D. Habicher, S. Korner and S. Al-Malaika, Polym. Degrad. Stab., 1997, 55, 217-224.

11 J. Pospisil, Polym. Degrad. Stab., 1993, 39, 103-109.

12 T. Nishiyama, T. Sugimoto and Y. Andoh, Polym. Degrad. Stab., 2001, 74, 189-193.

13 J. Wang, W. Ji and X. J. Zhang, Chem. Ind. Eng. Prog., 2008, 7, 1114-1118.

14 T. Nishiyama, Y. Andoh, T. Sugimoto and O. Tomoyuki, Polym. Degrad. Stab., 2003, 81, 409-413.

15 C. Q. Li, J. Wang, M. M. Ning and H. P. Zhang, J. Appl. Polym. Sci., 2012, 124, 4127-4135.

16 D. A. Tomalia, H. Baker, J. Dewaid, M. Hall, G. Kallos, S. Martin, J. Roeck, J. Ryder and P. Smith, Macromolecules, 1986, 19, 2466-2468.

17 K. Mishra, H. Ojha and N. K. Chaudhury, Food Chem., 2012, 130, 1036-1043.

18 C. Q. Li, Y. J. Wei, W. G. Shi, J. Wang and B. H. Wang, Prog. React. Kinet. Mech., 2015, 40, 279-290.

19 S. Roy, S. Mallick, T. Chakraborty, N. Ghosh, A. K. Singh, S. Manna and S. Majumdar, Food Chem., 2015, 173, 11721178. 
20 D. Villaño, M. S. Fernández-Pachón, M. L. Moyá, A. M. Troncoso and M. C. García-Parrilla, Talanta, 2007, 71, 230-235.

21 R. E. Hage, D. Perrin and N. Brosse, Nat. Resour., 2012, 3, 29-34.
22 M. Carocho and I. C. F. R. Ferreira, Food Chem. Toxicol., 2013, 51, 15-25.

23 J. Xie and K. M. Schaich, J. Agric. Food Chem., 2014, 62, 42514260.

24 M. C. Foti, J. Agric. Food Chem., 2015, 63, 8765-8776. 